\title{
Maternal Characteristics and the Effects of Early and Late-onset Types of Preeclampsia on Maternal and Perinatal Complications
}

\author{
Sintia Damayanti1,2), Sri Sulistyowati1,2), Ari Natalia Probandari3) \\ 1)Department of Obstetrics and Gynecology, Dr. Moewardi Hospital \\ 2)Faculty of Medicine, Universitas Sebelas Maret \\ 3)Department of Public Health, Faculty of Medicine, Universitas Sebelas Maret
}

\begin{abstract}
Background: Preeclampsia is still the main cause of morbidity and mortality not only for mothers but also for fetal. The concept of early and late-onset preeclampsia is a more modern concept, and it is stated that these two entities have different etiologies and must be considered as different forms of the disease. This study aims to analyzing differences in maternal characteristics (age, number of parity, history of hypertension and diabetes mellitus) and laboratory results (platelet, ewitz, Lactic Acid Dehydrogenase/LDH) and to analyzing differences in maternal complications (maternal death, eclampsia, impending eclampsia, pulmonary edema, (hemolysis, elevated liver enzyme levels, and low platelet levels/HELLP syndrome) and perinatal complications (perinatal death, Intrauterine Growth Restriction/IUGR, fetal hypoxia and fetal distress) between early and late-onset preeclampsia. This study aimed to investigate the maternal characteristics and the effects of early and late-onset types of preeclampsia on maternal and perinatal complications.

Subjects and Method: This was a retrospective cohort study. The study was carried out at Dr. Moewardi Hospital, Surakarta, from January 1, 2016, to December 31, 2017. A total of 548 pregnant mothers with preeclampsia was selected for this study. The dependent variable was the incidence of preeclampsia. The independent variables were age, parity, hypertension, diabetes Mellitus, platelets, LDH, and proteinuria. The data were obtained from the medical record and analyzed by a multiple linear regression.

Results: The number of patients with early-onset (162) was less than late-onset (386). More patients have multiparity in early and late-onset. In early-onset preeclampsia, thrombocytopenia and LDH increase tend to be present, and ewitz $>+1$. Early-onset preeclampsia tends to result in more maternal and perinatal complications.
\end{abstract}

Conclusion: The incidence of early-onset is less than late-onset, but early-onset provides worse complications for both maternal and perinatal.

Keywords: Early-onset preeclampsia, late-onset preeclampsia, characteristics, maternal and perinatal complications

\section{Correspondence:}

Sintia Damayanti. Department of Obstetrics and Gynecology, Dr. Moewardi Hospital/ Faculty of Medicine, Universitas Sebelas Maret, Surakarta, Central Java, Indonesia. Email: sintiadamayanti84@yahoo.co.id. Mobile: 082220020829.

\section{BACKGROUND}

Preeclampsia is still the main cause of morbidity and mortality not only for mothers but also for fetal (Ananth and Wapner, 2013). In the world, the prevalence of preeclampsia is around 5\% $-15 \%$ of all pregnancies (Srinivas et al., 2009).In Indonesia, 30\%-40\% ofcases of preeclamp- sia are the cause of death in pregnant women and 30\%-50\% are the cause of perinatal death. Specifically for hypertension in pregnancy, including preeclampsia, is found in persistent numbers and tends to increase in $5 \%-7 \%$ of pregnancies and is the most frequent medical complication in pregnancy. About 70\% of women diagnosed 
with hypertension in pregnancy are preeclampsia. At the Dr. Moewardi Hospital, Surakarta, the mortality rate of pregnant women in 2012 caused by preeclampsia was $63.30 \%$ in which 19 women died from the total of 30 pregnant women and in 2013 was $57.14 \%$ in which 12 women died from the total of 21 pregnant women (Sulistyowati et al., 2016).

Preeclampsia is diagnosed when a normotensive pregnant woman at first, after 20 weeks of pregnancy her blood pressure is higher than $140 / 90 \mathrm{mmHg}$, with or without proteinuria, followed by thrombocytopenia, pulmonary edema and organ lesions that affect the end organs such as kidneys, brain or liver (ACOG, 2013).The mother and fetus are at high risk of getting complications that will be very detrimental if the right action is not implemented earlier.

The exact etiology of preeclampsia is still unclear, suspected endothelial dysfunction plays an important role in the development of preeclampsia (Mateus et al., 2011). Until now there is no effective treatment that has been found to prevent preeclampsia, other than giving birth to a fetus and placenta (Woods et al., 2011).

The complications arising from preeclampsia are including eclampsia, hemolytic-elevated liver enzymes and low platelets (HELLP syndrome), Disseminated Intravascular Coagulopathy (DIC), emergency hypertension, encephalopathy hypertension and blindness of the cerebral cortical region (Cunningham et al., 2013).

Preeclampsia is divided into gestational age $<34$ weeks (early-onset) and gestational age $\geq 34$ weeks of (late-onset). The concept of early and late-onset preeclampsia is a more modern concept, and it is stated that these two entities have different etiologies and must be considered as differrent forms of the disease. Early-onset pre- eclampsia is caused by placentation disorders in which there is a disturbance of spiral arterial remodeling in myometrial and also trophoblast invasion in the spiral arteriolar wall. In late-onset preeclampsia, a hypothesis is found regarding the maternal constitution which causes maternal endothelial damage which has nothing to do with damage due to trophoblastic invasion.

\section{SUBJECTS AND METHOD}

\section{Study Design}

This was a retrospective cohort study conducted at the Dr. Meowardi Hospital, Surakarta, Central Java from January 1, 2016, to December 31, 2017.

\section{Population and Sampling}

The population in this study was all pregnant mothers with preeclampsia. The patient's data were collected from medical records of Dr. Moewardi Hospital, Surakarta by holding on to the code of severe preeclampsia, namely O14.1 within a period of two years, January 1, 2016, until December 31,2017 . A total of 548 pregnant mothers was selected for this study. With inclusion criteria are all data on preeclampsia patients who gave birth at the Dr. Moewardi Hospital, Surakarta with the ICD 10 code number is O14.1 and exclusion criteria are all patient data from Dr. Moewardi Hospital, Surakarta which is not with ICD 10 code number 014.1 and incomplete data.

\section{Study Variable}

The dependent variable was the incidence of preeclampsia. The independent variables were age, parity, hypertension, diabetes mellitus, platelets, LDH, and ewitz (proteinuria).

\section{Data Analysis}

The analysis used univariate, bivariate (Chisquare), and multiple linear regression with 95\% confidence intervals and $\mathrm{p}<0.05$, and processed using SPSS (Software Package 
for Social Science) software. The study was approved by the ethics committee Dr. Moewardi Hospital on April 24, 2018, with the number of 521 / IV / HREC / 2018.

\section{RESULTS}

From the data obtained it was found that there were 1845 deliveries over a period of Table 1. Sample Characteristics

\begin{tabular}{|c|c|c|c|c|c|c|c|}
\hline \multirow{3}{*}{ Variables } & \multicolumn{4}{|c|}{$\begin{array}{l}\text { Preeclampsia } \\
\end{array}$} & \multirow{3}{*}{$\mathbf{O R}$} & \multirow{3}{*}{$95 \%$ CI } & \multirow{3}{*}{$\mathbf{p}$} \\
\hline & \multicolumn{2}{|c|}{$\begin{array}{c}\text { Early-onset } \\
(n=162)\end{array}$} & \multicolumn{2}{|c|}{$\begin{array}{c}\text { Late-onset } \\
(n=386)\end{array}$} & & & \\
\hline & $\mathbf{N}$ & $\%$ & $\mathbf{N}$ & $\%$ & & & \\
\hline \multicolumn{8}{|l|}{ Age } \\
\hline$<20$ years old & 4 & 2.5 & 13 & $3 \cdot 4$ & & & 0.714 \\
\hline 20-34 years old & 99 & 61.1 & 236 & 61.1 & & & \\
\hline$>34$ years & 59 & 36.4 & 137 & $35 \cdot 5$ & & & \\
\hline \multicolumn{8}{|l|}{ Parity } \\
\hline 1 & 38 & $23 \cdot 5$ & 125 & 32.4 & 1.13 & 1.01 to 1.26 & 0.037 \\
\hline$>1$ & 124 & 76.5 & 261 & 6.6 & & & \\
\hline \multicolumn{8}{|c|}{ History of Hypertension } \\
\hline No & 105 & 64.8 & 257 & 66.6 & 1.05 & 0.81 to 1.35 & 0.691 \\
\hline Yes & 57 & 35.2 & 129 & $33 \cdot 4$ & & & \\
\hline \multicolumn{8}{|l|}{ History of DM } \\
\hline No & 146 & 90.1 & 364 & 93.1 & 1.73 & 0.93 to 3.21 & 0.079 \\
\hline Yes & 6 & 9.9 & 22 & 6.9 & & & \\
\hline \multicolumn{8}{|c|}{ Thrombocytopenia } \\
\hline $\mathrm{No}(\geq 100,000)$ & 120 & 74.1 & 351 & 90.9 & 2.85 & 1.89 to 4.30 & $<0.001$ \\
\hline Yes( $<100,000)$ & 42 & 25.9 & 35 & 9.1 & & & \\
\hline \multicolumn{8}{|l|}{ LDH } \\
\hline No $(<600 U / 1)$ & 90 & 55.6 & 346 & 89.6 & 4.28 & 3.05 to 6.02 & $<0.001$ \\
\hline Yes $(>600 \mathrm{U} / \mathrm{l})$ & 72 & 44.4 & 40 & 10.4 & & & \\
\hline \multicolumn{8}{|l|}{ Ewitz } \\
\hline+1 & 47 & 29.0 & 233 & 60.4 & 1.79 & 1.53 to 2.09 & $<0.001$ \\
\hline$>+1$ & 115 & 71.0 & 153 & 39.6 & & & \\
\hline
\end{tabular}

Table 1 showed there was no significant difference in maternal age characteristics between early-onset preeclampsia and lateonset preeclampsia $(\mathrm{p}=0.850)$. There was a significant difference between parity of early and late-onset preeclampsia mothers $(\mathrm{OR}=1.13 ; \mathrm{p}=0.037)$, where early-onset preeclampsia was $76.5 \%$ with parity $>1$, while late-onset preeclampsia was $67.6 \%$ with parity $>1$ time. There was no signifycant difference in the incidence of hypertension between early-onset preeclampsia and late-onset preeclampsia $(p=0.690)$. There was no significant difference in the incidence of diabetes mellitus between two years, patients with the preeclampsia code O14.1 obtained 548 patient data. From these data, the number of patients with early-onset preeclampsia was 162 patients (29.60\%) and 386 patients (70.40\%) with late-onset preeclampsia. early-onset preeclampsia and late-onset preeclampsia $(\mathrm{p}=0.079)$. There was a significant difference in the incidence of thrombocytopenia between early and late-onset preeclampsia $(\mathrm{OR}=2.85 ; \mathrm{p}<0.001)$, where early-onset preeclampsia was $25.9 \%$ with platelets <100,000, while late-onset preeclampsia $9.1 \%$ with platelets <100.000. There was a significant difference in the incidence of $\mathrm{LDH}>600$ between earlyonset preeclampsia and late-onset preeclampsia $(\mathrm{OR}=4.28 ; \mathrm{p}<0.001)$, where early-onset preeclampsia patients were 44.4\% with $\mathrm{LDH}>600$, whereas late-onset preeclampsia patients were $10.4 \%$ with 
$\mathrm{LDH}>600$. There was a significant differrence in the incidence of quality proteinuria $>+1$ between early-onset preeclampsia and late-onset preeclampsia $(\mathrm{OR}=1.79 ; \mathrm{p}$ $<0.001$ ), where early-onset preeclampsia patients were $71.0 \%$ with proteinuria $>+1$, whereas preeclampsia patients late-onset $39.6 \%$ with proteinuria $>+1$. In this study the distribution for proteinuria $>+1$, which means $+2,+3$ and +4 , the distribution obtained is +2 by $53 \%,+3$ by $39 \%$, and +4 by $8 \%$.

\section{Table 2. Maternal Complication}

\begin{tabular}{|c|c|c|c|c|c|c|c|}
\hline \multirow[t]{2}{*}{ Variables } & \multicolumn{2}{|c|}{$\begin{array}{c}\text { Early-onset } \\
(n=162)\end{array}$} & \multicolumn{2}{|c|}{$\begin{array}{c}\text { Late-onset } \\
(n=386)\end{array}$} & \multirow[t]{2}{*}{ OR } & \multirow[t]{2}{*}{$95 \% \mathrm{CI}$} & \multirow[t]{2}{*}{$\mathbf{p}$} \\
\hline & $\mathbf{N}$ & $\%$ & $\mathbf{N}$ & $\%$ & & & \\
\hline \multicolumn{8}{|c|}{ Maternal death } \\
\hline No & 151 & 93.2 & 384 & 99.5 & 13.10 & 2.93 to 58.46 & $<0.001$ \\
\hline Yes & 11 & 6.8 & 2 & 0.5 & & & \\
\hline \multicolumn{8}{|l|}{ Eclampsia } \\
\hline No & 145 & 89.5 & 371 & 96.1 & 2.70 & 1.38 to 5.27 & 0.003 \\
\hline Yes & 17 & 10.5 & 15 & 3.9 & & & \\
\hline \multicolumn{8}{|c|}{ Impending Eclampsia } \\
\hline No & 134 & 82.7 & 330 & 85.5 & 1.19 & 0.78 to 1.80 & 0.436 \\
\hline Yes & 28 & $17 \cdot 3$ & 56 & 14.5 & & & \\
\hline \multicolumn{8}{|c|}{ Pulmonary edema } \\
\hline No & 128 & 79.0 & 363 & 94.0 & 3.52 & 2.14 to 5.78 & $<0.001$ \\
\hline \multirow{2}{*}{\multicolumn{8}{|c|}{ HELLP syndrome }} \\
\hline & & & & & & & \\
\hline No & 81 & 50.0 & 351 & 90.9 & $5 \cdot 51$ & 3.88 to 7.83 & $<0.001$ \\
\hline Yes & 81 & 50.0 & 35 & 9.1 & & & \\
\hline
\end{tabular}

Table 2 showed that there was a significant difference in the incidence of maternal mortality between early-onset preeclampsia and late-onset preeclampsia $(\mathrm{OR}=13.10 ; \mathrm{p}<0.001)$, where early-onset preeclampsia patients were $6.8 \%$ and lateonset $0.5 \%$. There was a significant differrence in eclampsia between early and lateonset preeclampsia $(\mathrm{OR}=2.70 ; \mathrm{p}=0.003)$, where early-onset preeclampsia patients were $10.50 \%$ while late-onset $3.90 \%$. There was no significant difference in the incidence of impending eclampsia between early and late-onset preeclampsia ( $\mathrm{p}=$ 0.410). There was a significant difference in the incidence of pulmonary edema between early and late-onset preeclampsia $(\mathrm{OR}=$ 3.52; $\mathrm{p}<0.001$ ), where early-onset preeclampsia patients were $21 \%$ and $6 \%$ lateonset patients with pulmonary edema. There was a significant difference in HELLP syndrome incidence between early and late-onset preeclampsia $(\mathrm{OR}=5.51$; $\mathrm{p}<0.001$ ), where early-onset preeclampsia patients were $50 \%$ while late-onset $9.1 \%$ with HELLP syndrome.

Table 3 showed that there was a significant difference in the incidence of perinatal mortality between early and lateonset preeclampsia $(\mathrm{OR}=8.45 ; \mathrm{p}<0.001)$ in which early-onset preeclampsia patients were $43.8 \%$ while $5.2 \%$ of late-onset preeclampsia with perinatal mortality. There was a significant difference in the incidence of IUGR between early and late-onset preeclampsia $(\mathrm{OR}=6.18 ; \mathrm{p}<0.001)$, where early-onset preeclampsia patients were $51.2 \%$, while late-onset was $8.3 \%$ with IUGR. There was a significant difference in the incidence of fetal distress/hypoxia between early and late-onset preeclampsia $(\mathrm{OR}=2.88 ; \mathrm{p}<0.001)$, where early-onset preeclampsia patients were $56.8 \%$ while late-onset $19.7 \%$ with fetal distress/ hypoxia. 
Table 3. Perinatal Complication

\begin{tabular}{|c|c|c|c|c|c|c|c|}
\hline \multirow[t]{2}{*}{ Variables } & \multicolumn{2}{|c|}{$\begin{array}{c}\text { Early-onset } \\
(n=162)\end{array}$} & \multicolumn{2}{|c|}{$\begin{array}{c}\text { Late-onset } \\
(n=386)\end{array}$} & \multirow[t]{2}{*}{ OR } & \multirow[t]{2}{*}{$95 \% \mathrm{CI}$} & \multirow[t]{2}{*}{$\mathbf{p}$} \\
\hline & $\mathbf{N}$ & $\%$ & $\mathbf{N}$ & $\%$ & & & \\
\hline \multicolumn{8}{|c|}{ Perinatal death } \\
\hline No & 91 & 56.2 & 366 & 94.8 & 8.45 & 5.33 to 13.41 & $<0.001$ \\
\hline Yes & 71 & 43.8 & 20 & 5.2 & & & \\
\hline \multicolumn{8}{|l|}{ IUGR } \\
\hline No & 79 & 48.8 & 354 & 91.7 & 6.18 & 4.29 to 8.89 & $<0.001$ \\
\hline Yes & 83 & 51.2 & 32 & 8.3 & & & \\
\hline \multicolumn{8}{|c|}{ Fetal Hypoxia/Fetal } \\
\hline Distress & & & & & & & \\
\hline No & 70 & 43.2 & 310 & 80.3 & 2.88 & 2.26 to 3.67 & $<0.001$ \\
\hline Yes & 92 & 56.8 & 76 & 19.7 & & & \\
\hline
\end{tabular}

Table 4. Multivariate Analysis Effect of Maternal Characteristics on the Incidence of Preeclampsia

\begin{tabular}{lcccc}
\hline \multirow{2}{*}{ Variables } & \multirow{2}{*}{ OR } & \multicolumn{2}{c}{ 95\% CI } & \multirow{2}{*}{ p } \\
\cline { 3 - 4 } & & Lower limit & Upper limit & \\
\cline { 3 - 4 } Age & & & & 0.815 \\
20-34 years & 0.91 & 0.270 & 3.090 & 0.791 \\
>34 years & 0.85 & 0.240 & 3.076 & 0.183 \\
Parity (>1) & 1.40 & 0.853 & 2.308 & 0.476 \\
Hypertension (Yes) & 0.84 & 0.541 & 1.332 & 0.216 \\
Diabetes Mellitus (Yes) & 1.62 & 0.752 & 3.530 & 0.038 \\
Platelets (<100.0oo) & 1.81 & 1.033 & 3.175 & $<0.001$ \\
LDH (>600) & 4.37 & 2.668 & 7.185 & $<0.001$ \\
Proteinuria (>+1) & 2.14 & 1.369 & 3.345 & \\
\hline
\end{tabular}

Table 4 showed that greatly influence the incidence of late-onset preeclampsia are $\mathrm{LDH}$ variables, with $<0.001$ and $\mathrm{OR}=4.37$ (2.66 to 7.18), where patients with $\mathrm{LDH}>$ 600 are at risk for early-onset preeclampsia 4.37 (2.66 to 7.18). Other variables that affected were proteinuria $(\mathrm{p}=0.001$ and $\mathrm{OR}=2.14(1.36$ to 3.34$)$ and platelets $\mathrm{p}=$ 0.038 and $\mathrm{OR}=1.81$ (1.03 to 3.17).

\section{DISCUSSION}

\section{The effect of maternal age towards preeclampsia}

There was no significant difference in maternal age characteristics between early-onset preeclampsia and late-onset preeclampsia $(p=0.850)$. In this study both show that the age range of 20 to 34 years is the age at which preeclampsia is more common both early and late-onset. This research is in accordance with the theory which states that nutrition in pregnant women plays a role in the incidence of preeclampsia, where women aged $>30$ years the level of micronutrients in the blood during pregnancy is lower when compared to young age (Danielle et al., 2014).

\section{The effect of parity towards pre- eclampsia}

There was a significant difference between parity of early and late-onset preeclampsia mothers where early-onset preeclampsia was $76.5 \%$ with parity $>1$, while late-onset preeclampsia was $67.6 \%$ with parity $>1$ time. The results of this study indicate that the characteristics of preeclampsia women are more directed at parity $>1$, which is related to maternal stress factors. A large 
number of children (multiparous) is one of the causes of maternal stress. Psychological events such as high-stress levels, anxiety or depression can directly or indirectly affect pregnancy because it causes preeclampsia. Psychological stress can affect up to $18 \%$ in pregnant women, where there is a change in the functioning of the neuroendocrine system and the immune system. Dangerous conditions can directly change the hypothalamic-pituitary-adrenal (HPA) axis, which leads to increased cortisol levels and related changes in cellular immunity. High cortisol levels are associated with hypertension and endothelial dysfunction (Priscila et al., 2011).

\section{The effect of hypertension towards preeclampsia}

This study shows no significant difference in the incidence of hypertension between early-onset preeclampsia and late-onset preeclampsia. This is in line with research in Washington, which states that hypertension can be at risk for mothers with early and late-onset preeclampsia (Lisonkova and Joseph, 2013).

\section{The effect of diabetes mellitus to- wards preeclampsia}

This study shows no significant difference in the incidence of diabetes mellitus between early-onset preeclampsia and lateonset preeclampsia. This is in line with research in Washington, which states that a history of Diabetes mellitus can be at risk in mothers with early and late-onset preeclampsia (Lisonkova and Joseph, 2013).

\section{The effect of thrombocytopenia to- wards preeclampsia}

This study shows a significant difference in the incidence of thrombocytopenia between early and late-onset preeclampsia where early-onset preeclampsia was $25.9 \%$ with platelets $<100.000$, while late-onset preeclampsia $9.1 \%$ with platelets $<100.000$.

\section{The effect of LDH towards pre- eclampsia}

This study shows a significant difference in the incidence of $\mathrm{LDH}>600$ between earlyonset preeclampsia and late-onset preeclampsia where early-onset preeclampsia patients were $44.4 \%$ with $\mathrm{LDH}>600$, whereas late-onset preeclampsia patients were $10.4 \%$ with $\mathrm{LDH}>600$ This is in line with research conducted in women in America with results in early-onset of lesions in the placenta that cause abnormalities in the umbilical arteries and uterine arteries, resulting in lysis, thrombocytopenia, IUGR, HELLP syndrome. Whereas, for late-onset, there is no significant disturbance in the placenta, commonly seen in patients with obesity and cardiovascular disease (Mifsud and Sebire, 2014).

\section{The effect of quality proteinuria to- wards preeclampsia}

This study shows a significant difference in the incidence of quality proteinuria $>+1$ between early-onset preeclampsia and lateonset preeclampsia where early-onset preeclampsia patients were $71.0 \%$ with proteinuria $>+1$, whereas preeclampsia patients late-onset $39.6 \%$ with proteinuria $>+1$. In this study the distribution for proteinuria $>+1$, which means $+2,+3$ and +4 , the distribution obtained is +2 by $53 \%,+3$ by $39 \%$, and +4 by $8 \%$. This is related to the basic theory of early-onset preeclampsia that results from trophoblast invasion which causes endothelial damage to blood vessels throughout the maternal body (Mifsud and Sebire, 2014).

\section{The effect of maternal mortality to- wards preeclampsia}

This study shows a significant difference in the incidence of maternal mortality between early-onset preeclampsia and lateonset preeclampsia where early-onset preeclampsia patients were $6.8 \%$ and lateonset $0.5 \%$. Research in women in the 
Netherlands concluded that early-onset preeclampsia causes more maternal and infant morbidity and mortality (Boundewijn, 2008).

\section{The effect of eclampsia towards preeclampsia}

This study shows a significant difference in eclampsia between early and late-onset preeclampsia where early-onset preeclampsia patients were $10.50 \%$ while late-onset $3.90 \%$. This is consistent with research in Turkish women, concluding that earlyonset preeclampsia increases the risk of maternal mortality by twenty times compared with late-onset preeclampsia (Halenur et al., 2015).

\section{The effect of impending eclamp-} sia towards preeclampsia

This study shows no significant difference in the incidence of impending eclampsia between early and late-onset preeclampsia. Where early-onset preeclampsia patients were $17.30 \%$ and late-onset were $14.50 \%$ with impending eclampsia.

\section{The effect of pulmonary edema towards preeclampsia}

This study shows a significant difference in the incidence of pulmonary edema between early and late-onset preeclampsia where early-onset preeclampsia patients were $21 \%$ and $6 \%$ late-onset patients with pulmonary edema. It is stated that early-onset preeclampsia is preeclampsia that has occurred at $<34$ weeks gestation and is more due to trophoblast invasion that has occurred at a young gestational age, resulting in long enough endothelial damage in the maternal body which can cause disturbances in the body's circulation increased pulmonary capillary permeability that causes pulmonary edema (Peter et al., 2003).

12. The effect of HELLP syndrome towards preeclampsia

This study shows a significant difference in HELLP syndrome incidence between early and late-onset preeclampsia where earlyonset preeclampsia patients were 50\% while late-onset $9.1 \%$ with HELLP syndrome. This is consistent with studies that mention early-onset preeclampsia is associated with higher maternal, perinatal morbidity and mortality, especially in cases such as eclampsia and HELLP syndrome (Hutcheon et al., 2011).

\section{The effect of perinatal mortality to- wards preeclampsia}

This study shows a significant difference in the incidence of perinatal mortality between early and late-onset preeclampsia in which early-onset preeclampsia patients were $43.8 \%$ while $5.2 \%$ of late-onset preeclampsia with perinatal mortality. It was stated that in early-onset outcomes of neonatal deaths were higher than late-onset (Simsek et al., 2016).

\section{The effect of IUGR towards pre- eclampsia}

This study shows a significant difference in the incidence of IUGR between early and late-onset preeclampsia where early-onset preeclampsia patients were $51.2 \%$, while late-onset was $8.3 \%$ with IUGR. This study is in accordance with studies in African women, found that fetuses with IUGR output were found in early-onset patients, and were not found in late-onset (Gathiram and Moodley, 2016).

\section{The effect of fetal distress/ hypoxia towards preeclampsia}

This study shows a significant difference in the incidence of fetal distress/hypoxia between early and late-onset preeclampsia where early-onset preeclampsia patients were $56.8 \%$ while late-onset $19.7 \%$ with fetal distress/hypoxia. This is in line with the results of research in Bandung, Indonesia. It was concluded that the incidence of early-onset was less than late-onset, perinatal complications in the form of IUGR and fetal asphyxia were obtained in 
early-onset preeclampsia (Aziz and Johanes, 2016).

From this study, it is known that maternal characteristics that greatly influence the incidence of late-onset preeclampsia are LDH variables where patients with $\mathrm{LDH}>600$ are at risk for early-onset preeclampsia 4.37 (2.66 to 7.18 ). Other variables that affected were proteinuria and platelets. These results prove that the theory of the causes of preeclampsia is not only due to trophoblast invasion causes the failure of spiral artery remodeling, but is also influenced by the maternal constitution (Creasy, 2014).

The most common complication in early and late-onset preeclampsia is to look at the OR values for each maternal and perinatal complication. The results showed that maternal mortality was the most common complication, followed by complications of perinatal death and complications of IUGR. This is in accordance with previous studies which stated that maternal and perinatal mortality increased 16 times in early-onset preeclampsia (Lisonkova and Joseph, 2013).

Characteristics of patients with early and late-onset are more likely to lead to multiparity groups, this is related to maternal stress factors that have an impact on the incidence of preeclampsia. A large number of children (multiparity) is one of the causes of maternal stress. Psychological events such as high-stress levels, anxiety or depression can directly or indirectly affect pregnancy because it causes preeclampsia. Psychological stress can affect up to $18 \%$ in pregnant women, where there is a change in the functioning of the neuroendocrine system and the immune system. Dangerous conditions can directly change the hypothalamic-pituitary-adrenal (HPA) axis, which leads to increased cortisol levels and related changes in cellular immunity. High cortisol levels are associated with hypertension and endothelial dysfunction. Earlyonset preeclampsia tends to cause maternal complications (maternal death, eclampsia, pulmonary edema, HELLP syndrome) and perinatal complications (perinatal death, IUGR, and fetal distress/ fetal hypoxia).

\section{AUTHOR CONTRIBUTION}

Sintia Damayanti collected the data and wrote the manuscript. Sri Sulistyowati examined data and analyze the data. Ari Natalia Probandari suggested the discussion.

\section{FUNDING AND SPONSORSHIP}

This study used the authors' independent fund.

\section{ACKNOWLEDGMENT}

We would like to thank the Medical Record Installation of General Dr. Moewardi Hospital Surakarta for giving permission to take the data.

\section{CONFLICT OF INTEREST}

There was no conflict of interest in this study.

\section{REFERENCE}

$\overline{\text { ACOG (2013). Management of hypertensive }}$ crisis in pregnancy, American College of Obstetricians and Gynecologists. Optimizing Protocols in Obstetrics. 4: 1-6. Retrieved from http://www.ilpqc.org/docs/htn/Recognition/ACO GDII(NY)KeyElementsManagementH ypertensiveCrisisPregnancy.pdf

Ananth CV, Wapner RJ (2013). Pre-eclampsia rates in the United States, 19802010: An age-period-cohort analysis. British Medical Journal. 347: 65-4. https://doi.org/10.1136/bmj.f6564. 
Aziz A, Johannes C (2016). The differences of characteristic, management, maternal, and perinatal outcomes among early and late-onset preeclampsia. Open Access Library Journal. 3: 27-50. http://dx.doi.org/10.4236/oalib.1102750.

Creasy R (2014). Maternal-Fetal Medicine. Principle and practice, America: Saunders. 7: 756S.

Cunningham FG, Donald MPC, Gant NF, Leveno KJ, Gilstrap LC, Hankins GDF (2013). Williams Obstetrics. 22th ed. London: Prentice-Hall International. 567-618.http://dx.doi.org/10.4236/ojpm.2014.411097.

Danielle A, Samita S, Gita D (2014). The association between dietary factors and gestational hypertension and preeclampsia: a systematic review and meta-analysis of observational studies. BMC Medicine. 12:157. https://doi.org/10.1186/s12916-014-0157-7.

Gathiram P, Moodley (2016). Pre-eclampsia: its pathogenesis and pathophysiology. Cardiovascular Journal of Africa. 27(2): 77. https://dx.doi.org/10.5830\%2FCVJA-2016-009.

Halenur B, Fatma B, Kadir G, Sedef R, Esra A, Ilke T, Ahmet G (2015). The frequency and fetomaternal outcomes of early-and late-onset preeclampsia: The experience of a single tertiary health center in the bustling metropolis of Turkey; Istanbul. Medeniyet Medical Journal. 30: 163-169. https://dx.doi.org/10.5222/MMJ.2015.163.

Hutcheon JA, Lisonkova S, Joseph KS (2011). Epidemiology of preeclampsia and the other hypertensive disorders of pregnancy. Best Practice Clinical Obstetrics Gynaecol. 25(4):391-403. doi: 10.1016/j.bpobgyn.2011.01.006
Lisonkova S, Joseph KS (2017). Incidence of preeclampsia: Risk factors and outcomes associated with early-versus late-onset disease. American Journal of Obstetrics \& Gynecology. 209(544): 1-12.https://doi.org/10.1016/j.ajog.2013.08.019.

Mateus J, Bytautiene E, Lu F, Tamayo E, Betancourt A, Hankins G (2011). Endothelial growth factor therapy improves pre-eclampsia like manifestation in Murine model induced by expression of SVEGR-1. American Journal of Physiological Society. 30(5): 1781-7. https://doi.org/10.1152/ajpheart.00373.2011.

Mifsud W, Sebire N (2014). Fetal Diagnosis and Therapy: Placental pathology in early-onset and late-onset fetal growth restriction. London: Karger. 36: 117. https://doi.org/10.1159/ooo359969.

Peter V, Laura A, James M, Robert M (2003). Sub classification of preeclampsia. Hypertension in pregnancy. 22(2): 143-148. https://doi.org/10.1081/PRG-120021060.

Priscila V, Moises E, Dinara D, Jose A (2011). Distress conditions during pregnancy may lead to pre-eclampsia by increasing cortisol levels and altering lymphocyte sensitivity to glucocorticoids. Elsevier. 77: 188-191. https://doi.org/10.1016/j.mehy.2011. 04.007.

Simsek A, Uludag S, Tuten A, Oncul M, Acikgoz AS, Uludag S (2016). Maternal and prenatal outcomes in earlyonset and late-onset preeclampsia. Department of Obstetrics and Gynecology. Istanbul. $15^{\text {th }}$ World Congress in Fetal Medicine. Retrieved from https://fetalmedicine.org/abstracts/2016/var/pdf/abstracts/o1542.pdf. 
Srinivas S, Edlow A, Neff, Sammel M, Andrela C, Elovitz M (2009). Rethinking IUGR in pre-eclampsia: dependent or independent of maternal hypertension? Journal of Perinatology. 29: 680-684. https://doi.org/10.1038/jp.2009.83.

Sulistyowati S, Soetrisno S, Kartika NH (2016). Ekspresi human leukocyte antigen-C di trophoblastdan natural killer cell di desiduapada preeklampsia berat. Jurnal Kedokteran Brawi- jaya. 29(1): 59-63. Retrieved from https://jkb.ub.ac.id/index.php/jkb/ar ticle/view/1154/499.

Woods A, Hoffmann D, Weydert C, Butler S, Zhou Y, Sharma R (2011). Adenoviral delivery of VEGF 121 early in pregnancy prevents spontaneous development of pre-eclampsia in $\mathrm{BPH} / 5$ Mice. Hypertension. American Heart Association. 94-102. https://doi.org/10.1161/HYPERTENSIONAHA.110.160242. 